\title{
AKTIVITAS ANTIJAMUR SEDIAAN GEL DENGAN BAHAN AKTIF EKSTRAK ETANOL DAUN TURI (SESBANIA GRANDIFLORA L)
}

\author{
Yuyun Arlita ${ }^{1}$, Vina Maulidya ${ }^{1}$, Laode Rijai ${ }^{1}$ \\ ${ }^{1)}$ Laboratorium Riset dan Pengembangan Farmaka Tropis \\ Fakultas Farmasi, Universitas Mulawarman, Samarinda \\ *Email : Yuyunarlita@gmail.com
}

\begin{abstract}
Has conducted research antifungal activity test of leaf Sesbania grandiflora $L$ which aims to determine the antifungal activity of the leaves of Sesbania grandiflora $L$ by observing the inhibition zone extracts and preparations gel to mold Malasezzia furfur. Antifungal activity of the extract was determined using the agar diffusion method. The results showed that there is inhibition of fungal growth. The antifungal activity of leaf extract Sesbania grandiflora $L$ with a concentration of $2.5 \%, 5 \%, 7.5 \%$ and $10 \%$ tested against fungi Malasezzia furfur, the best concentration present in a concentration of $7.5 \%$ to mold Malasezzia furfur. Base gel made with a concentration of $1 \%, 1.5 \%$ and $2 \%$, with the main ingredient Carbopol, best gel base concentration present in concentrations of $1 \%$ were tested for organoleptic and physical, then mixed base $1 \%$ to $2.5 \%$ and tested eksstrak activity antifungal. Inhibition zone extract compared with gel preparations that have been made.
\end{abstract}

Keywords: Diffusion Agar, Gel, Formulation, Antifungals.

\begin{abstract}
ABSTRAK
Telah dilakukan penelitian uji aktivitas antijamur dari daun Sesbania grandiflora L yang bertujuan untuk mengetahui aktivitas antijamur dari daun Sesbania grandiflora L yaitu dengan mengamati zona hambat ekstrak dan sediaan gel terhadap jamur Malasezzia furfur. Aktivitas antijamur ekstrak ditentukan menggunakan metode difusi agar. Hasil penelitian menunjukkan bahwa ada penghambatan pertumbuhan jamur. Aktivitas antijamur ekstrak daun turi dengan konsentrasi 2,5\%, 5\%,7,5\% dan 10\% diuji terhadap jamur Malasezzia furfur, konsentrasi terbaik terdapat pada konsentrasi 7,5\% terhadap jamur Malasezzia furfur. Basis gel dibuat dengan konsentrasi 1\%, 1,5\% dan 2\% dengan bahan utama carbopol, konsentrasi basis gel terbaik terdapat pada konsentrasi $1 \%$ yang diuji secara organoleptis dan fisik, kemudian dicampurkan basis $1 \%$ dengan eksstrak 2,5\% dan diuji aktivitas antijamur. Zona hambat ekstrak dibandingkan dengan sediaan gel yang telah dibuat.
\end{abstract}

Kata Kunci: Difusi Agar, Gel, Formulasi, Antijamur. 


\section{PENDAHULUAN}

Antijamur adalah obat-obat atau senyawa yang digunakan untuk menghilangkan infeksi yang disebabkan oleh jamur. Infeksi oleh jamur dapat terjadi pada kulit oleh dermatofit (jamur yang hidup di atas kulit) dan selaput lendir mulut, (Departemen Farmakologi, 2012).

Tanaman obat merupakan sumber bahan obat tradisional yang banyak digunakan secara turun-temurun. Salah satu tanaman yang dimanfaatkan yaitu turi (Sesbania grandifora L.). Bagian tanaman yang digunakan sebagai obat ialah bunga, daun dan kulit batang. Bagian daun turi sendiri sering digunakan sebagai obat pereda nyeri, luka dan keputihan. Menurut Nurwahidah (2011), daun turi berkhasiat untuk sebagai antibakteri dan antijamur karena mengandung metabolit sekunder seperti tanin dan saponin. Dengan demikian, peneliti tertarik untuk menguji aktivitas antimikroba dari bagian daun tanaman turi tersebut dan diformulasikan menjadi sediaan gel, karena semakin tingginya minat masyarakat dalam penggunaan obat dengan bahan alam atau bahan tradisional maka pembuatan sediaan obat berbasis bahan alam sangat baik dikembangkan.

\section{METODOLOGI PENELITIAN}

\section{BAHAN}

Bahan yang digunakan dalam penelitian ini antara lain daun turi, Na-metabisulfit, carbopol 940, gliserin, TEA, benang godam, aquades, $\mathrm{NaCl}$, kertas saring, papper disc, etanol, kapas dan medium SDA.

\section{ALAT}

Alat yang digunakan dalam penelitian ini antara lain alat-alat gelas, timbangan analitik, spatel, sendok tanduk, magnetik stirrer, hotplate, sudip, laminar iar flow, autoklaf, jarum ose, inkubator, gunting, lemari pendingin, $\mathrm{pH}$ meter, plat kaca, timbangan gram, mikrometer sekrup, rak tabung reaksi, spiut, seperangkat alat maserasi, bunsen dan seperangkat alat rotary evaporator.

Penelitian ini dilakukan di Laboratorium Riset dan Pengembangan Farmaka Tropis Fakultas Farmasi Universitas Mulawarman pada bulan Agustus 2016 hingga September 2016. 


\section{PROSEDUR}

\section{PEMBUATAN GEL}

Gel yang dibuat dalam penelitian ini yaitu :

\begin{tabular}{cccc}
\hline Bahan & FA & FB & FC \\
\hline Carbopol 940 & 0.05 & 0.1 & 0.15 \\
Na-metabisulfit & 0.01 & 0.01 & 0.01 \\
Gliserin & 0.04 & 0.04 & 0.04 \\
TEA & 0.04 & 0.06 & 0.08 \\
Aquades & Ad 10 & Ad 10 & Ad 10
\end{tabular}

*) Bahan dalam satuan gram

\section{EVALUASI FISIK SEDIAAN GEL EKSTRAK DAUN TURI}

a. Uji organoleptik

Pengujian organoleptik dilakukan dengan mengamati sediaan gel dari bentuk, bau, dan warna sediaan

b. Uji pH gel

Sebanyak 0,5 g gel ektrak daun Turi diencerkan dengan $5 \mathrm{ml}$ aquades, kemudian $\mathrm{pH}$ stik dicelupkan selama 1 menit. Perubahan warna yang terjadi pada $\mathrm{pH}$ stik menunjukkan nilai $\mathrm{pH}$ dari gel.

c. Uji homogenitas

Sediaan gel pada bagian atas, tengah, dan bawah diambil kemudian diletakkan pada plat kaca lalu digosok dan diraba.

d. Uji daya sebar

Sebanyak 0,5 gr gel diletakkan diatas kaca bulat yang berdiameter $15 \mathrm{~cm}$, kaca lainnya diletakkan diatasnya dan dibiarkan selama 1 menit. Diameter sebar gel diukur. Setelahnya, ditambahkan 100 gr beban tambahan dan didiamkan selama 1 menit lalu diukur diameter yang konstan (Anief, 2007).

\section{PEMBUATAN SUSPENSI JAMUR}

Jamur Malasezzia furfur yang telah dibiakkan dari biakan murni kemudian ditambahkan dengan $\mathrm{NaCl}$ sebanyak $10 \mathrm{ml}$ dikerjakan secara aseptis 


\section{PENGUJIAN AKTIVITAS ANTIJAMUR}

Disiapkan 5 cawan petri yang telah berisi medium SDA kemudian cawan petri ditandai dan dibagi mejadi 5 bagian, kemudian dimasukkan papper disc yang telah dicelupkan ke dalam ekstrak atau gel ekstrak dimana tiap-tiap bagian digunakan untuk pengujian yaitu ekstrak dengan konsentrasi 2.5\%, 5\%, 7.5\%, 10\%, dan gel dengan ekstrak 2.5\%. Diinkubasi $2 \times 24$ jam pada suhu $5^{\circ} \mathrm{C}$, setelah itu diukur zona hambat yang terbentuk pada medium dengan menggunakan mikrometer sekrup.

\section{ANALISIS DATA}

\section{HASIL DAN PEMBAHASAN}

Pengujian organoleptik yang dilakukan dengan mengamati sediaan gel berdasarkan bentuk, warna, dan bau :

\begin{tabular}{cccc}
\hline Konsentrasi & Bentuk & Warna & Bau \\
\hline $1 \%$ & Semisolid & Bening transparan & Bau khas Na-metabisulfit \\
$1.5 \%$ & Semisolid & Bening transparan & Bau khas Na-metabisulfit \\
$2 \%$ & Semisolid & Bening transparan & Bau khas Na-metabisulfit \\
\hline
\end{tabular}

Uji organoleptik terhadap basis gel menunjukkan bahwa semakin tinggi jumlah carbopol yang digunakan maka dapat mempengaruhi viskositas sediaan, semakin banyak jumlah carbopol yang digunakan maka semakin kental pula sediaan.

Tabel $\mathrm{pH}$ basis gel

\begin{tabular}{cc}
\hline Konsentrasi & $\mathrm{pH}$ \\
\hline $1 \%$ & 5.04 \\
$1.5 \%$ & 5.25 \\
$2 \%$ & 5.51 \\
\hline
\end{tabular}

Uji $\mathrm{pH}$ yang dilakukan pada tiap sediaan basis gel diperoleh nilai $\mathrm{pH}$ yang berbedabeda untuk tiap sediaan. Pengukuran $\mathrm{pH}$ dilakukan dengan menggunakan $\mathrm{pH}$ meter yang dilakukan dengan cara memasukkan stik pH meter kedalam sediaan. Variasi basis gel memiliki pH yang sesuai dengan kriteria ph kulit manusia yaitu 4,5 sampai 6,5 sehingga aman untuk digunakan, karena $\mathrm{pH}$ yang terlalu asam dapat menyebabkan iritasi kulit sedangkan $\mathrm{pH}$ yang terlalu basa dapat membuat kulit bersisik. 
Tabel Daya Sebar

\begin{tabular}{cccc}
\hline Beban yang Diberikan & $1 \%$ & $1.5 \%$ & $2 \%$ \\
\hline $25 \mathrm{~g}$ & 8.30 & 5.13 & 4.10 \\
$50 \mathrm{~g}$ & 8.73 & 5.30 & 4.33 \\
$75 \mathrm{~g}$ & 9.06 & 5.43 & 4.43 \\
$100 \mathrm{~g}$ & 9.30 & 5.56 & 4.56 \\
$125 \mathrm{~g}$ & 9.53 & 5.86 & 4.66 \\
$150 \mathrm{~g}$ & 9.70 & 6.06 & 4.76 \\
\hline
\end{tabular}

Pengujian daya sebar untuk tiap sediaan dengan variasi tipe basis dilakukan untuk melihat kemampuan sediaan menyebar pada kulit, dimana suatu basis gel sebaiknya memiliki daya sebar yang baik untuk menjamin pemberian bahan obat yang memuaskan.Perbedaan daya sebar sangat berpengaruh pada kecepatan difusi zat aktif dalam melewati membran. Semakin luas membran tempat sediaan menyebar maka koefisien difusi makin besar yang mengakibatkan difusi obat pun semakin meningkat, sehingga semakin besar daya sebar suatu sediaan maka makin baik (Hasyim et al., 2012). Perbedaan daya sebar antara tiap basis yang digunakan terjadi karena konsistensi dari tiap basis gel yang digunakan. Basis gel dengan konsentrasi carbopol yang lebih tinggi menyebabkan daya sebar semakin menurun.

Tabel Aktivitas Antijamur

\begin{tabular}{cc}
\hline Sampel & Daya Hambat \\
\hline Ekstrak 2.5\% & 5.86 \\
Ekstrak 5\% & 8.23 \\
Ekstrak 7.5\% & 12.54 \\
Ekstrak 10\% & 9.27 \\
Gel dengan ekstrak 2.5\% & 15.16 \\
\hline
\end{tabular}

Antijamur merupakan obat-obat atau senyawa yang digunakan untuk menghilangkan infeksi yang disebabkan oleh jamur, infeksi oleh jamur dapat terjadi pada kulit yang disebabkan oleh jamur dermatofit atau jamur yang hidup di atas kulit (Departemen Farmakologi dan Terapeutik, 2012).

Daun turi memiliki aktivitas antijamur karena memiliki kandungan metabolit sekunder antara lain flavonoid, tanin, dan ssaponin yang terbukti memiliki aktivitas antijamur. Aktivitas antijamur ekstrak ditentukan menggunakan metode difusi agar. Hasil 
penelitian menunjukkan bahwa ada penghambatan pertumbuhan jamur. Aktivitas antijamur ekstrak daun turi dengan konsentrasi 2,5\%, 5\%, 7,5\% dan $10 \%$ diuji terhadap jamur Malasezzia furfur, konsentrasi terbaik terdapat pada konsentrasi 7,5\% terhadap jamur Malasezzia furfur. Sedangkan untuk sediaan gel dengan kandungan ekstrak 2,5\% memiliki aktivitas antijamur yang meningkat 3 kali lebih kuat dari ekstraknya.

\section{KESIMPULAN}

1. Konsentrasi basis terbaik yaitu basis dengan konsentrasi $1 \%$.

2. Konsentrasi ekstrak yang memiliki aktivitas terbaik dalam menghambat perumbuhan jamur Malasezzia furfur adalah ekstrak dengan konsentrasi 7,5\%.

3. Formulasi ekstrak $2.5 \%$ menjadi sediaan gel dapat meningkatkan aktivitas antijamur menjadi 3 kali lipat.

\section{DAFTAR PUSTAKA}

Anief, M. 2007. Farmasetika. Gadjah Mada University Press, Yogyakarta.

Departemen Farmakologi dan Terapeutik. 2012. Farmakologi dan Terapi Edisi 5. Badan Penerbit FKUI : Jakarta.

Nurwahidah. 2011. Aktivitas Antimikroba Ekstrak Daun Turi (SESBANIA

GRANDIFLORA L.) terhadap Mikroba CANDIDA ALBICANS, PSEUDOMONAS

AERUGINOSA, dan STAPHYLOCOCCUS AUREUS 